\title{
Social integration of people with a migration background in Swiss sport clubs: A cross-level analysis
}

\author{
Matthias Buser ${ }^{1}$, Jenny Adler Zwahlen², Torsten Schlesinger ${ }^{3}$, Siegfried Nagel ${ }^{1}$ \\ ${ }^{1}$ Institute of Sport Science, University of Bern, Bern, Switzerland \\ ${ }^{2}$ Special Department for Integration and Prevention, Federal Office for Sport, Magglingen, \\ Switzerland \\ ${ }^{3}$ Faculty of Sport Science, Ruhr-University Bochum, Germany
}

\section{Correspondence}

Matthias Buser

Institute of Sport Science, University of Bern, Bremgartenstrasse 145, CH-3012 Bern, Switzerland.

matthias.buser@ispw.unibe.ch

\begin{abstract}
Sport clubs are considered an ideal setting for the social integration of people with a migration background (PMB). However, they can also be a place of social closure practices, where assimilative ideas and ethnic boundaries are present. Besides the individual characteristics of the members, adequate club organizational structures are relevant for preventing social closure and facilitating social integration. Thus, the role of organizational structures for social integration might differ between natives and PMB. Based on data from 42 Swiss sport clubs and 780 sport club members, with and without a migration background, we analyzed individual (migration background, membership biography) and structural factors (situational, club goals, club culture) using multilevel models and tested cross-level interactions between structural variables and migration background. The results reveal that membership biography (e.g. membership duration and volunteering) and migration background are relevant for social integration. The estimated cross-level effects reveal that, unlike for natives and second-generation $\mathrm{PMB}$, structural conditions are especially relevant for first-generation $\mathrm{PMB}$. For example, social integration increases with a higher proportion of PMB in the club or a less assimilative club culture.
\end{abstract}

\section{Keywords}

Social integration, migration background, sport clubs, multilevel analysis, cross-level interaction

\section{Introduction}

The social integration of people with a migration background (PMB) and existing resentments of natives towards immigrants are important problems faced by immigration countries. In Europe, voluntary sport clubs (VSCs) are often considered to play an important role in addressing these challenges and serve as a significant integration catalyst (European commission, 2007; Nagel et al., 2020b). VSCs provide an ideal setting for encounters between people from different cultures, reduce prejudices through interethnic contact (Makarova and Herzog, 2014), and promote social cohesion and networks (Agergaard, 2019; Burrmann et al., 2020; Nagel et al., 2020b). 
In Switzerland, about one quarter of the population is active in over 19,000 VSCs. While the national Sport Promotion Act explicitly refers to the role of sport in social cohesion, there are only few and selective national or regional (cantonal) funding arrangements for the integrative efforts of VSCs due to the principle of subsidiarity (Nagel et al., 2020b). PMB are around $40 \%$ of the population in Switzerland, yet are underrepresented in VSCs, but differences to Swiss natives are decreasing over recent years (Lamprecht et al., 2017).

Empirical studies confirm the connection between VSC membership and the development of social networks and contacts for members in general (Becker and Häring, 2012; Elmose- $\varnothing$ sterlund et al., 2019; Hoye et al., 2015) and for PMB (Janssens and Verweel, 2014; Kleindienst-Cachay et al., 2012; Makarova and Herzog, 2014). However, universal expectations concerning the social integration achieved by VSCs have been questioned. Like other social settings, VSCs can be a place of social closure practices. Various studies reveal that in VSCs discrimination, assimilationist ideas, or ethnic boundaries can exclude rather than integrate PMB (e.g. Burrmann et al., 2017; Dowling, 2020; Elling and Claringbould, 2005; Krouwel et al., 2006; Spaaij, 2013). Club structures and culture seem to play an important role here (Elling and Claringbould, 2005; Seiberth et al., 2013; Seiberth and Thiel, 2010). For example, exclusionary practices can arise from a club culture orientated towards tradition if it rejects any deviation from established practices (Seiberth et al., 2013).

This illustrates that membership of a VSC indicates little about the level of integration in a club (Seiberth and Thiel, 2010). Integration only becomes visible through the degree and pattern of involvement across different communication patterns and action contexts of a VSC, for example the extent to which PMB feel accepted or build intercultural friendships (Adler Zwahlen et al., 2018; Kleindienst-Cachay et al., 2012; Nagel et al., 2020a).

Focused on social integration in VSCs, two research gaps can be identified. (1) There is a lack of empirical knowledge on how characteristics of members and club structures together facilitate or hinder social integration. While studies have applied a multilevel approach to members in general (Elmose- $\emptyset$ sterlund et al., 2019; Østerlund and Seippel, 2013), there are none specific to PMB. Recent articles have explicitly called for factors at the club level to be included in studies on social integration of PMB (Adler Zwahlen et al., 2019; Nagel et al., 2020a). This article builds on this and innovatively 
contributes to the field by using a multilevel approach that considers individual characteristics of members together with general club structures (e.g. club size) and specific club structures related to the integration of PMB (e.g. integration culture).

(2) Regardless of migration status, members are part of the same social context. However, it is unlikely that structural factors have the same relevance for different members. For example, it could be assumed that PMB benefit from intercultural club structures in more specific ways, while natives, who are less likely to experience exclusion, depend less on them. To assess such structural differences, attention must be paid to the interplay between structural features and the migration background of members. This article therefore considers cross-level interactions and provides new insight into the differing effects of general and integration-specific structures on social integration of natives and PMB.

Building on this, the following research questions are addressed: (1) What role do individual and structural factors play in the social integration of sport club members? (2) To what extent does the role of structural factors in VSCs on social integration differ between natives and PMB? The results help to determine relevant mutually controlled individual and structural factors in VSCs that are related to the social integration of club members with and without a migration background. Thus, decisionmakers in VSCs as well as sports policy makers may gain a clearer picture of effective integration. The role of club structures is particularly important as this is managed by the clubs themselves, and therefore can be changed to become more integrative.

\section{VSCs as social settings for social integration}

According to Esser (2009), the social integration of individual actors into social systems-such as a VSC-can take place along four interdependent dimensions. Culturation means the acquisition of knowledge, skills, and habits. Placement represents the acquisition of rights and the filling of positions. Identification captures the emotional bond with a group. Finally, interaction means the integration into central interpersonal networks by establishing and maintaining functioning (intercultural) social relationships.

Our study focuses on social integration in the social setting of VSCs. For this purpose, we rely on a measurement instrument developed and published prior to this article (Adler Zwahlen et al., 
2018). The instrument systematically applied Esser's concept to the context of VSCs. The empirical analysis of this article focuses on interaction, a central dimension to the establishment of social networks and further integration into society (Esser, 2009), and a central dimension inherent to VSCs. In VSCs, conceptualized as interest communities (Coleman, 1974), members realize a common, overreaching goal through collective action. Membership is voluntary but requires a willingness to contribute individual resources to a collective pool of resources. Thus, members decide not to do individual, informal sport based on their own resources but to do joint sport activities together with others based on the pooled resources (Nagel, 2006).

Therefore, membership in a VSC with its different opportunity structures (Gelegenheitsstrukturen) brings a wealth of recurring and institutionalized (intercultural) occasions for interaction with people with similar interests (Kleindienst-Cachay et al., 2012; Makarova and Herzog, 2014). Before, during and after sport activities, VSCs provide a high level of informal communication opportunities, where different members can interact and connect. Thus, (intercultural) contact can develop based on sport-specific knowledge, leading to mutual acceptance (Kahlert, 2009).

However, intercultural interactions in sports clubs can also be problematic and permeated with unfamiliarity, strangeness, and conflict. Such experiences are cemented or reduced by interactions (Seiberth, 2012). Therefore, a key issue is the extent to which contact leads to mutual acceptance and reduction of social distance, as postulated by the contact hypotheses (Gerber and Pühse, 2017; Makarova and Herzog, 2014). Here, the club context and how it values intercultural diversity and openness is central (Elling and Claringbould, 2005; Seiberth et al., 2013).

\section{Individual and structural factors of interaction in VSCs}

The analysis of interaction as a special form of social action in VSCs presupposes an examination of the institutional structures and their normative anchoring in terms of a more or less predictable cultural environment (Albert, 2005). In short, the logic of the situation must be considered (Weber, 1980 [1921]). This addresses a basic requirement for action analyses within VSCs, namely, the connection between the social actions of club members and the institutional context in VSCs, whose social effects are likely to become apparent as specific patterns of thought and action ("habit formation") in 
everyday club life. Therefore, the analysis of social integration needs to consider differences of the members at the individual level together with structural differences of the clubs at the club level (Nagel, 2006).

\section{Structural factors of the clubs}

Structural differences between VSCs and their role in the interaction of the members can be illustrated using Felds (1981) concept of foci. VSCs can be seen as foci, defined as "social, psychological, legal or physical entities around which joint activities are organized" (Feld, 1981: 1016). Feld argues that foci place participants in rewarding situations, creating positively valued interactions (cf. Becker and Häring, 2012). However, foci differ in their potential to "transform mere contact opportunities into interaction by bringing together people with similar interests in a mutually rewarding situation" (Stauder, 2014). This potential varies with communication patterns in the foci, the fluctuation of participants, the extent of focus overlap, and the transitivity of friendships.

In small or rural municipalities, there are only a few foci available, thus, "everybody joins these foci and consequently there is more focus overlap" (Stauder, 2014). This simplifies the consolidation of friendship relations because members also meet in foci other than the VSC. Therefore, members in rural clubs often interact face-to-face and in close social networks (Baur, 2003). In larger clubs, consolidation of relationships is more difficult, because fluctuation of members in club activities is higher and the transitivity of friendships is lower than in small clubs. Studies confirm that interaction is more pronounced in smaller clubs (Elmose- $\varnothing$ sterlund et al., 2019; Østerlund and Seippel, 2013). We therefore hypothesize that the degree of interaction is more pronounced in smaller clubs and in clubs in smaller municipalities.

Interaction is likely to be influenced by communication patterns associated with club goals. Clubs with high sociability goals might gather members more often and more intensively in nonsporting communication and activities (Elmose- $\varnothing$ sterlund et al., 2019). The focus on competitive sport promotes additional contact (e.g. through games) and consolidation opportunities (Kleindienst-Cachay et al., 2012). Therefore, it can be assumed that a higher competition goal and a higher sociability goal promote interaction of the club members. 
While certain structural factors influence all club members in similar ways, there may also be structures that explicitly influence interaction barriers for PMB. Regarding the competition goal, it can be assumed that PMB additionally profit from a subordinate role of ethnicity compared to performance-orientated aspects in competition-oriented clubs (Kalter, 2005). The goal of integrating PMB is likely linked to a positive connotation of integration. Although not all clubs might translate such goals into suitable programmes (Seiberth et al., 2013), we hypothesize that PMB show more interaction, on average, in clubs with a higher integration goal. While natives might depend less on integration goals, they could profit from additional contact opportunities.

A higher proportion of PMB in the club can be an indication of openness to cultural diversity. Kalter (2005) showed that PMB on teams with a higher proportion of foreigners are less exposed to social distances and stereotypes. The pool of similar interaction partners for PMB is also likely to increase with the proportion of PMB, especially if members share an ethnic background. We therefore hypothesize that interaction of PMB increases with the proportion of PMB in the club. Positive effects for natives are not expected. Although social distances to PMB is reduced in heterogeneous clubs, it is not likely to occur in homogeneous clubs in the first place.

Despite a club's general openness, social closure processes can occur if club culture is "not compatible with a positive concept of diversity" (Seiberth et al., 2013: 190, own translation). An exclusionary culture can arise from widespread stereotypes held outside the club, which also become embedded within it. It can also arise if the club culture itself is orientated towards preserving tradition. In such situations, a common approach to cultural diversity is the demand for assimilation (Seiberth, 2012). Sport-related assimilation refers to an integration strategy in which PMB give up references to their origin and adapt exclusively to the typical behaviour patterns of their club. In contrast, pluralism means that PMB maintain references to their cultural origin and identity (Adler Zwahlen et al., 2019; Berry, 2005; Esser, 2009). Gerber and Pühse (2017) showed that young PMB prefer pluralistic integration strategies. Therefore, assimilative integration demands in VSCs are problematic for integration processes (Dowling, 2020; Elling and Claringbould, 2005; Kleindienst-Cachay et al., 2012; Mutz, 2011) because PMB are pressured to avoid displaying "otherness" in the club (KleindienstCachay et al., 2012) and are more likely to experience strangeness in relationships (Seiberth, 2012). It 
can be assumed that interaction of PMB decreases with an assimilative understanding of integration in the club, while an intercultural, pluralistic understanding increases it. Negative effects of an assimilative understanding are not expected for natives. However, it is possible that the homogenizing function of assimilative adaptation will strengthen the interactions of established members.

\section{Individual characteristics of the members}

To understand individual differences in members interactions we differentiate between human capital and sport-related consumer capital (Heckmann, 2015, Nagel et al., 2020a). Human capital relates to socio-biographical characteristics (e.g. migration status, sex). Differences are likely to arise with migration status. Unlike natives and second-generation migrants $\left(\mathrm{PMB}_{2 \mathrm{G}}\right)$, first-generation migrants $\left(\mathrm{PMB}_{1 \mathrm{G}}\right)$ are likely to be most confronted with cultural distance and a lack of familiarity with expectations in local VSCs due to their socialization in the country of origin (Adler Zwahlen et al., 2019; Heckmann, 2015). Various authors find less interaction for $\mathrm{PMB}_{1 \mathrm{G}}$ than for $\mathrm{PMB}_{2 \mathrm{G}}$ and natives (Adler Zwahlen et al., 2019; Nagel et al., 2020a). We hypothesize that PMB and here especially $\mathrm{PMB}_{1 \mathrm{~g}}$ experience fewer positive interactions than natives. Further sociodemographic characteristics are not linked to interaction in VSCs. Only for older people were negative connections confirmed (ElmoseØsterlund et al., 2019; Østerlund and Seippel, 2013). In analyses specific to PMB, age, sex, and education status were irrelevant (Adler Zwahlen et al., 2019; Nagel et al., 2020a). Nevertheless, these variables are utilized as controls.

Sport-related consumer capital indicates the accumulated knowledge and importance of different goods (e.g. social events) in the VSC, and is strongly related to membership-biographical characteristics. With increasing duration and intensity of membership, members accumulate clubrelated consumer capital. Connections between interaction and membership duration, volunteering, frequency of activity or participation in competitive sport have been repeatedly demonstrated (Adler Zwahlen et al., 2019; Elmose- Østerlund et al., 2019; Nagel et al., 2020a; Østerlund and Seippel, 2013). Adler Zwahlen et al. (2019) also point to the socializing effects of parental (past) VSC activity. We hypothesize that membership duration, volunteering, frequency of activity, participation in competitive sport, and parental club activity are associated with more interaction. 
In addition, it should be emphasized that structures at the club level may not only have a direct effect on interactions of the members, but also influence the strength of the connection between individual characteristics and interaction. Assuming that the migration status is less relevant in clubs open to interculturality, this can only be tested by the interrelation between the predictors of migration status (individual) and intercultural club culture (structural). This means that in addition to the independent variables of the individual and structural levels, cross-level effects also need to be considered in the model. Following the argument of cultural distance and the lack of familiarity with expectations in local VSCs, we assume here that integration-specific structures are especially relevant for $\mathrm{PMB}_{1 \mathrm{G}}$.

\section{Method}

\section{Sample}

The empirical analyses utilize data from a cross-sectional study of 42 Swiss VSCs. With the aim to survey VSCs with different integration-specific structures, six disciplines with different participation rates by PMB were theoretically selected (football, basketball, martial arts, gymnastics, mountain sport, and skiing; cf. Lamprecht et al., 2014). However, even though a variety of clubs and disciplines were surveyed, the sample cannot be viewed as representative. A club official (usually the president) was interviewed and asked about the club's organizational structures in a paper questionnaire. Seven clubs were in municipalities with fewer than 5,000 inhabitants, and nine in municipalities with more than 50,000 inhabitants. Fourteen clubs had fewer than 200 members, while 17 had more than 400 members. The proportion of PMB was below 10 percent in 17 clubs and above 25 percent in 17 clubs. Club officials selected training groups within their organization, where members with and without a migration background, aged 16-30 years, completed a questionnaire on social integration in the club, membership biography, and sociodemographic characteristics. Trained, multilingual staff supported individual interviewees with language comprehension. The 780 surveyed members $(38.0 \%$ women) had an average age of 20.6 years (SD $=4.0$ years) and had been sport club members for 6.8 years (SD $=5.4$ years), on average. In addition, 254 members (32.6 percent) were first- or secondgeneration migrants $\left(98 \mathrm{PMB}_{1 \mathrm{G}}, 156 \mathrm{PMB}_{2 \mathrm{G}}\right.$ ). The surveyed $\mathrm{PMB}$ were distributed among 33 clubs 
$\left(\mathrm{PMB}_{1 \mathrm{G}}\right.$ in 26 clubs, $\mathrm{PMB}_{2 \mathrm{G}}$ in 27 clubs). $\mathrm{PMB}_{1 \mathrm{G}}$ were born in Western and Northern Europe (22.7\%), Southeast and Eastern Europe (26.6\%), Southern Europe (6.7\%), North America (8.0\%), South America (13.3\%), Africa (9.3\%) and Asia (13.3\%). Eleven persons fled to Switzerland (12.2\%). Parents of PMB 2 had nationalities from countries in Western and Northern Europe (11.5\%), Southeast and Eastern Europe (18.0\%), Southern Europe (21.2\%), South America (6.4\%), Africa (5.8\%) and Asia (10.3\%). Parents of the remaining $\mathrm{PMB}_{2 \mathrm{G}}(24.4 \%)$ have become Swiss.

Due to incomplete questionnaires, 59 cases ( 7.5 percent) were excluded from the preliminary analysis of the individual-level variables. This dropped to 39 cases (5.0 percent) for the joint analysis of the club-level and individual-level variables. Therefore, the results for the estimated models are based on a sample of 741 members (238 PMB) in 42 clubs. On average, 17.6 members (5.7 PMB) were considered per club. ${ }^{1}$

\section{Operationalization of variables}

The dependent variable interaction stems from a previously developed measurement instrument for analysing the multidimensional social integration in VSCs. The reliability and validity of the instrument was successfully checked through confirmatory factor analysis for PMB and natives, with the results published at an earlier stage (cf. Adler Zwahlen et al., 2018). The items were measured on a five-point scale, from "does not apply" to "fully applies". The four items on interaction asked about the establishment and existence of social relationships as well as intercultural conflicts and acceptance, which can permeate interactions. The items were "Other members respect me the way I am" (after Elmose- $\varnothing$ sterlund et al., 2016), "No one in the club would notice my absence" (developed), "I find it difficult to make social contacts in our club" (developed) and "In our club, conflicts often arise between me and members from other backgrounds" (adapted from Baur and Burrmann, 2003). The last three items were inverted for the analysis. Table 1 shows the descriptive statistics.

\footnotetext{
${ }^{1}$ In seven clubs, fewer than five members were surveyed. This is not problematic for multilevel analysis. Maas and Hox (2005) find no negative effects on estimators or standard errors for extremely unbalanced group sizes. Snijders and Bosker (2012) confirm that group size can equal one as long as other groups are larger.
} 
The structural factors municipality size and club size were operationalized as the number of inhabitants and the number of club members. The proportion of PMB in the club was measured with six categories, according to Kleindienst-Cachay et al. (2012). Club goals were measured on a five-point scale, from "not important" to "very important". The sociability goal was gauged by the statement "Promoting sociability in the club" (from Nagel, 2006), the competition goal by "Engagement in topclass and competitive sport" (adapted from Baur et al., 2003), and the goal of integrating PMB by “Promoting the integration of PMB in the club" (adapted from Kleindienst-Cachay et al., 2012).

Knowing that club culture in general and club-specific understanding of integration is empirically difficult to grasp (Seiberth et al., 2013), members' individual attitudes towards the integration of PMB were aggregated at the club level (i.e. mean value per club) and tested as contextual variables for the collective understanding of integration, while individual attitudes were tested as controls at the individual level (aggregation of contextual variables; cf. Marsh et al., 2012). Theoretical support for such an approach can be found in Nagel (2006), who argues that club culture arises from the actions of individual members, influenced by their orientations and attitudes.

Individual integration attitudes were measured on a five-point scale, from "do not agree at all" to "agree completely". The item "PMB should not receive special treatment in sport clubs" (developed based on Baur and Mutz, 2009) was used as an indicator of an assimilative understanding of integration. As an indicator for an pluralistic understanding, the item "Values and cultural habits of PMB should be respected by the club and its members" (from Elmose- $\varnothing$ sterlund et al., 2016) was used. In addition, the item "If I could choose my own sport group, at least some athletes should come from my country of origin" (adapted from Kalter, 2005) was used as an indicator of a more general intercultural openness of the members. For higher values to show more intercultural openness, the item was inverted.

'Table 1 about here'

The individual factor migration background was measured generationally, according to Leszczensk and Gräbs Santiago (2015). $\mathrm{PMB}_{1 \mathrm{G}}$ were born in a foreign country and immigrated to 
Switzerland. $\mathrm{PMB}_{2 \mathrm{G}}$ were born in Switzerland but had at least one parent with foreign origin. It is important to note that $\mathrm{PMB}$ are very heterogeneous beyond migration generations and that these terms are used analytically without wanting to reconstruct differentiation categories. Sociodemographic variables (age, sex, and level of education) and club biographic variables (length of membership, volunteering, frequency of activity, participation in competitive sport, and parents' (former) participation in clubs) were also used. Table 1 shows the independent variables.

\section{Data analysis}

The data were prepared and analyzed with SPSS 26 and R 4.0.2. To consider the nested structure of the data and to test individual and contextual variables together as well as the interplay between them, multilevel models were implemented (using $\mathrm{R}$ package $\mathrm{nlme}$ ). The dependent variable, interaction, was non-independent of the clubs (intraclass correlation coefficient, ICC $=.109$ ). Therefore, multilevel analyses are appropriate (Hox, 2010). The sample is rather small at the contextual level, ${ }^{2}$ therefore, the models were calculated with restricted maximum likelihood, which provides more precise estimates of variance components and standard errors for small samples (Hox, 2010; Snijders and Bosker, 2012). To keep the models simple (Hox and MacNeish, 2020), structural factors were tested in groups of situational variables, club goals, and club culture. Individual variables were tested in advance and only relevant variables were further considered.

Differences in the role of structural effects on natives and PMB were tested by specifying crosslevel effects for the dummy variables $\mathrm{PMB}_{1 \mathrm{G}}$ and $\mathrm{PMB}_{2 \mathrm{G}}$. While the main effect of the structural variables shows the general effect only meaningful to natives, the cross-level effect shows the additional effect for $\mathrm{PMB}_{1 \mathrm{G}}$ and $\mathrm{PMB}_{2 \mathrm{G}}$, respectively. All variables except the dummies for migration background were grand mean centred (Hox, 2010). To interpret the actual effects of the predictors, unstandardized regression coefficients are reported (Hox, 2010).

Model diagnostics showed some deviations of the residuals from the normal distribution and homoskedasticity. Therefore, the models were validated in an ordered logistic multilevel model, which

\footnotetext{
${ }^{2}$ Kreft (1996) recommends a distribution of 50 groups and 20 group members (50/20) to calculate level-2 and cross-level effects. New simulation studies by Maas and Hox (2005) and MacNeish and Stapleton (2016), however, do not find negative effects on (cross-level) estimates and standard errors of smaller samples (30/5 and 14/10).
} 
treats the dependent variable categorically rather than metrically (Hox, 2010). This option makes no assumptions about the normal distribution of residuals and homoskedasticity. There are only few changes in the additional models, and notable differences are presented in the results.

\section{Results}

First, the individual-level variables were tested. An analysis of variance $(F(2,777)=17.02)$ showed significant differences in interaction between natives (mean $=4.45), \mathrm{PMB}_{2 \mathrm{G}}($ mean $=4.32)$, and $\mathrm{PMB}_{1 G}$ (mean $=4.04)$. Table 2 shows the results for the multilevel models for the individual-level variables, with an empty (zero) model (column 1) and a model including all individual-level variables (column 2). Relevant variables $(p \leq .10)$ were tested again in a third model (column 3). The fixed effects (marginal $\mathrm{R}^{2}$ ) of model 3 explain 10 percent of the total variance. Differences in the composition of members between clubs explain 36 percent of the variance on the club level.

In line with our expectations, the sociodemographic variables are irrelevant for interaction, unlike migration background. $\mathrm{PMB}_{1 \mathrm{G}}$ have significantly less interaction than natives. A weaker negative and non-significant effect exists for $\mathrm{PMB}_{2 \mathrm{G}}$. As expected, membership biographical variables membership duration, volunteering, and parents' (former) participation in VSCs are significantly and positively associated with interaction. Individual agreement with the assimilative item "No special treatment for PMB" is significantly connected with more interaction, as higher values might be related to individual conformity with club-specific norms. In addition, individual intercultural openness (rejection of "Athletes should come from country of origin") is relevant for interaction, perhaps because open members do not restrict themselves to communication with few other members. ${ }^{3}$

'table 2 around here'

Next, the structural factors were tested in three groups (situational variables, club goals, integration culture), together with the individual variables. For each group, Table 3 shows a model

\footnotetext{
${ }^{3}$ Frequency of activity is only below $p=0.10$ in the ordered logistic model $(0.08)$ but not in the main model $(0.15)$.
} 
without and a model with specification of cross-level effects. The fixed effects (marginal $R^{2}$ ) of the specified models now explain 13-17 percent of the total variance. The explained variance on club level increases to $42-60$ percent. Individual variables hardly change. ${ }^{4}$

The situational variables show that clubs in municipalities with fewer than 5,000 inhabitants and clubs with fewer than 200 members are significantly associated with higher interaction of members' in general but the proportion of PMB in the club is not (model 1). Natives do not show higher degrees of interaction with higher proportions of $\mathrm{PMB}$, as indicated by the non-significant main effect in model 2. Likewise, $\mathrm{PMB}_{2 \mathrm{G}}$ do not differ from natives, as indicated by the insignificant cross-level effect for $\mathrm{PMB}_{2 \mathrm{G}}$. However, the cross-level effect for $\mathrm{PMB}_{1 \mathrm{G}}$ is significant and positive. This means that the negative relationship between $\mathrm{PMB}_{1 \mathrm{G}}$ and interaction is significantly reduced when the proportion of PMB in a club increases. Our expectations regarding the positive relationship between interaction and the proportion of $\mathrm{PMB}$ in the club are therefore confirmed for $\mathrm{PMB}_{1 \mathrm{G}}{ }^{5}$

Club goals do not show significant effects for members in general (model 3). Cross-level effects reveal that $\mathrm{PMB}_{2 \mathrm{G}}$ do not differ significantly from natives. However, $\mathrm{PMB}_{1 \mathrm{G}}$ show significant positive cross-level effects for the competition goal and the integration goal. Higher levels of both goals are associated with a higher level of interaction of $\mathrm{PMB}_{1 \mathrm{G}}$. The expected positive effects for the competition and integration goals are therefore confirmed for $\mathrm{PMB}_{1 \mathrm{G}}{ }^{6}$

The collective understanding of integration is irrelevant for members in general (model 5), natives, or $\mathrm{PMB}_{2 \mathrm{G}}$, but $\mathrm{PMB}_{1 \mathrm{G}}$ show significant cross-level effects (model 6). Higher values of the

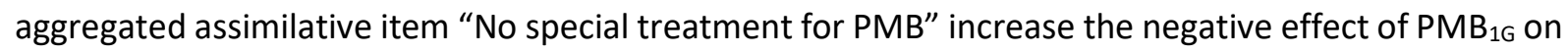
interaction, while a higher intercultural club culture (the inverted, aggregated item "Athletes should come from country of origin") reduces it. ${ }^{7}$ The aggregated pluralistic item "Respecting habits" shows a

\footnotetext{
${ }^{4}$ With specification of cross-level effects, the main effects of $\mathrm{PMB}_{1 \mathrm{G}}$ and $\mathrm{PMB}_{2 \mathrm{G}}$ change. These changes are due to the statistical procedure and are substantively meaningless. The direct effects should therefore not be interpreted alone, but only together with the cross-level effects. For further details, see Hox (2010).

${ }^{5}$ Cross-level effects were also tested for municipality size and club size. To avoid complicating the models, they were used as metric variables. No significant cross-level effects were found.

${ }^{6}$ Cross-level effects for the sociability goal were calculated for test purposes. The results show no relevant differences between member groups. Additionally, the sociability goal is closer to relevance in the ordered logistic models 4 and 5 ( $p=$ 0.08 and 0.13 ).

${ }^{7}$ The interaction of $\mathrm{PMB}_{1 \mathrm{G}}$ increases by $0.27+0.22=0.49$ if intercultural culture increases and assimilative culture decreases by one standard deviation. These values result from the main effect plus the cross-level effect weighted with the standard deviation (intercultural culture: $(-0.07+0.65) * 0.47=0.27$; assimilative culture: $(-0.01+-0.76) *-0.28=0.22)$. This means that there is no negative effect of $\mathrm{PMB}_{1 \mathrm{G}}$ on interaction in clubs with a corresponding integration culture.
} 
significant positive cross-level effect only when tested alone in the model (not shown). The expectations for PMB regarding club-cultural understanding of integration are thus confirmed for $\mathrm{PMB}_{1 \mathrm{G}}$.

'table 3 about here'

Finally, the significant variables were tested in a full model (model 7). The fixed effects of this model explain 20 percent of the total variance. At the club level, 63 percent of the variance is explained. This model is more complex, and the effect size of most variables decreases. The effects for small municipalities and clubs are no longer significant. However, club size remains relevant $(p \leq .10)$. Significant cross-level effects for PMB1G are confirmed for the collective understanding of integration. The proportion of PMB and the competition goal are still relevant $(p \leq .10)$, while the cross-level effect of the integration goal disappears. ${ }^{8}$

\section{Discussion}

This article analyses the social integration of VSC members with and without a migration background in terms of their interactions in the clubs. The innovative contribution is the analysis of interactions based on members' individual characteristics together with general and integration-specific club structures, as well as the cross-level analysis that tests the extent to which structural differences in social integration between natives, $\mathrm{PMB}_{1 \mathrm{G}}$ and $\mathrm{PMB}_{2 \mathrm{G}}$ exist. Even though all members are basically well integrated, individual and structural differences are found.

Regarding individual differences, intergenerational differences are visible for the migration background (see also Nagel et al., 2020a; Walseth, 2008). While $\mathrm{PMB}_{1 \mathrm{G}}$ are less likely to be involved in positive social contacts, $\mathrm{PMB}_{2 \mathrm{G}}$ are similar to natives as they are locally socialised and possibly less exposed to cultural distance than $\mathrm{PMB}_{1 \mathrm{G}}$. However, it would be wrong to hastily equate $\mathrm{PMG}_{2 \mathrm{G}}$ with

\footnotetext{
${ }^{8}$ The complexity of the full model also appears in deviations of the ordered logistic model: While the competition goal displays higher $(p>.10)$, club size $(p \leq .05)$ and municipality size $(p \leq .10)$ display lower $p$-values. Additionally, the uncertainty about the cross-level effect of "No special treatment ${ }_{a g g}$ " with $\mathrm{PMB}_{1 \mathrm{G}}$ is slightly higher in the ordered logistic models (model 6: $p=0.08$; full model: $p=0.05$ ).
} 
natives, as the negative effect approaches significance. In contrast to Nagel et al. (2020a), being born in a foreign country remains relevant when controlling for membership-biography. It is possible that the role of membership duration and volunteerism is less pronounced among younger members. However, membership-biography is relevant. This has repeatedly been shown (Elmose- $\varnothing$ sterlund et al., 2019; Nagel et al., 2020a; Østerlund and Seippel, 2013). Parents' (former) club participation, membership duration and volunteering are linked to having more pronounced social networks within the club. Yet, participation in competition sport and the frequency of activity within the club are not related to interaction of young members. However, the latter is only slightly irrelevant.

VSCs differ in their structural opportunities to promote interactions. Members in small clubs and in clubs in small municipalities have more interactions. Thus, members not only consolidate social networks through lower fluctuations in small clubs, but also through greater focus overlap in small municipalities. This has not been previously shown for small municipalities. Elmose- $\varnothing$ sterlund et al. (2019) showed negative, but non-significant effects using a metric variable and including clubs in larger municipalities. The sociability goals of clubs are not relevant, which contradicts the findings of Elmose$\emptyset$ sterlund et al. (2019), perhaps because abstract social goals are not translated into action and, therefore, do not reach members.

The role of the structural context differs with the migration status, illustrating the usefulness of the cross-level approach. Structural conditions are especially relevant for $\mathrm{PMB}_{1 \mathrm{G}}$. A higher proportion of $\mathrm{PMB}$, an intercultural and less assimilative collective understanding of integration and in part also competition-orientated club goals are connected to successful interactions of $\mathrm{PMB}_{1 \mathrm{G}}$. Competition-orientation reduces the importance of ethnic differences compared to sport skills. The proportion of PMB might reduce prejudice among club members (Kalter, 2005). An intercultural and less assimilative collective understanding of integration is likely to reduce otherness in interactions (Dowling, 2020; Kleindienst-Cachay et al., 2012; Seiberth, 2012). These structural conditions are not relevant to natives and $\mathrm{PMB}_{2 \mathrm{G}}$, pointing to intergenerational differences between $\mathrm{PMB}_{1 \mathrm{G}}$ and $\mathrm{PMB}_{2 \mathrm{G}}$ in club structural effects. This has not been shown previously. Other than $\mathrm{PMB}_{2 \mathrm{G}}$ and natives, $\mathrm{PMB}_{1 \mathrm{G}}$ are socialised abroad and may have on average fewer cultural and social techniques to cope with assimilative demands and therefore also benefit from interaction partners open to cultural diversity. 
Therefore, in contrast to Elmose- $\varnothing$ sterlund et al. (2019), we do not conclude that the structural context is less relevant compared to individual characteristics. While this seems true for natives and $\mathrm{PMB}_{2 \mathrm{G}}$, it is not for $\mathrm{PMB}_{1 \mathrm{G}}$.

Hence, decision-makers in VSCs and sport policies can attempt to manage club conditions to facilitate the integration of $\mathrm{PMB}_{1 \mathrm{G}}$. Here, an integration goal alone is not sufficient. Considering the proportion of PMB in the club and the collective understanding of integration, it is statistically irrelevant. This can be interpreted as the need to translate integration goals into action (Seiberth et al., 2013). Such efforts can aim to achieve an intercultural, less assimilative club culture or to increase the proportion of $\mathrm{PMB}$ in the club. Both aims seem relevant to integrate $\mathrm{PMB}_{1 \mathrm{G}}$ and are not detrimental to the integration of natives or $\mathrm{PMB}_{2 \mathrm{G}}$. Of course, practical applications should be done carefully. Our results mainly apply to mixed clubs with low to medium proportions of PMB. Yet, when promoting the participation of young PMB, care must also be taken to facilitate interethnic contact and avoid ethnic divides within the club. Also, $\mathrm{PMB}_{1 \mathrm{G}}$ are not a homogeneous group and practical applications should consider the heterogeneity that comes along with different migration and integration experiences.

\section{Limitations and future research}

The study has its limitations, and four methodological points should be noted. Firstly, regarding the independent variables, club cultural understanding of integration is based on single items, and scales measuring individual integration attitudes should be utilized in future surveys (cf. e.g. Baur and Mutz, 2009; Van Dick et al., 1997). The survey of club goals was based on the statements of club representatives whose perceptions can differ from those of club members, thus, a member perspective should be included. Secondly, the theoretical classification of the items to the dependent variable interaction may be developed further. In our study we rely on a systematic, published measurement instrument (Adler Zwahlen et al., 2018). Future studies should try to refine the measurement instrument by considering further aspects and items of interaction.

Thirdly, generalization of the results should be done with caution. Because of the nonrepresentativeness of the sample, this is especially true for descriptive inference. However, as we focus on causal inference and controlled for various factors, relevant factors for social integration are more 
likely to be consistent. Nagel (2020a) found only small variance in social integration between European countries, indicating that the country context was of limited relevance. Yet, generalizations to other countries should consider possible contextual differences. Future studies can show how individual and structural factors for social integration differ with the country context.

Fourthly, the results are based on cross-sectional data. Selection effects are possible for the participation of PMB in VSCs, where participation is the result of social integration into the host society (e.g. Lundkvist et al., 2020). For example, it might be possible that $\mathrm{PMB}_{2 \mathrm{G}}$ are not influenced by integration-specific structures, because less integrated $\mathrm{PMB}_{2 \mathrm{G}}$ did not join the clubs or even have left them again. Also, selection effects regarding the club structures (e.g. higher pluralistic integration attitudes if $\mathrm{PMB}_{1 \mathrm{G}}$ are better integrated) are unlikely from a theoretical perspective but cannot be ruled out methodologically. Therefore, longitudinal studies are needed to consider methodological problems such as endogeneity, intertemporal order on dependent and explanatory variables and timedelayed effects.

Future work should also address the following. First, an analysis of variance showed significant differences between sport disciplines (with the highest means for gymnastics, and the lowest for football) for members in general but not for PMB. However, to avoid complex models, sport disciplines were not included here in favour of theoretically more concrete structural factors. This seems appropriate, as it is not the disciplines themselves but the clubs' organizational structures that are relevant for social integration. Larger samples at the club level are advisable to elaborate on differences across sport disciplines.

Second, despite similar migration and integration experiences, PMB are not homogeneous (Agergaard, 2019). Other individual characteristics beyond the migration generation, such as values (e.g. orientation towards the host country) and lifestyles likely play an important role in integration processes. Larger samples are needed to consider this heterogeneity.

Third, this article considers interaction as a central dimension of social integration inherent to VSCs. Interaction can be an important factor for social integration in other dimensions (placement, identification, culturation; Esser, 2009). Structural factors of the clubs are likely to be relevant for social integration in these other dimensions as well, and future analyses should build on this. 
Fourth, the training group level is not considered in this paper, just as in former studies (Elmose- Østerlund et al., 2019; Nagel et al., 2020a; Østerlund and Seippel, 2013). Training groups within a club can be characterized by different social structures (e.g. group size, performance or sociability oriented groups). Therefore, it can be assumed that integration processes are not only influenced by club structures, but also by social constellations and conditions of the training group, where club members are mostly active.

\section{Acknowledgements}

We thank the clubs and their members for their participation in the study. Thank you also to the reviewers for their valuable comments on the earlier draft of the paper.

\section{Declaration of conflicting interests}

The authors declare no potential conflicts of interest with respect to the research, authorship, and/or publication of this article.

\section{Funding}

The authors disclosed receipt of the following forms of financial support for the research, authorship, and/or publication of this article: This work was supported by the Swiss Federal Office for Sport. 


\section{References}

Adler Zwahlen J, Nagel S and Schlesinger T (2018) Analyzing social integration of young immigrants in sports clubs. European Journal for Sport and Society 15(1): 22-42.

Adler Zwahlen J, Nagel S and Schlesinger T (2019) Zur Bedeutung soziodemografischer, sportbezogener und soziokultureller Merkmale für die soziale Integration junger Migranten in Schweizer Sportvereinen [On the importance of sociodemographic, sport-related and sociocultural characteristics for the social integration of young migrants in Swiss sports clubs]. Sport und Gesellschaft 16(2): 125-154.

Agergaard S (2019) Rethinking Sports and Integration: Developing a Transnational Perspective on Migrants and Descendants in Sports. London: Routledge.

Albert G (2005) Moderater methodologischer Holismus. KZfSS Kölner Zeitschrift für Soziologie und Sozialpsychologie 57(3): 387-413.

Baur J (2003) Vereine als Aktivitätskerne gemeindlichen Lebens? Über lokale Integrationsleistungen von Sportvereinen [Clubs as Activity Centers of Community Life? About local Integration Services of Sports Clubs]. In: Baur J and Braun S (eds) Integrationsleistungen von Sportvereinen als Freiwilligenorganisationen [Integration Services of Sports Clubs as Voluntary Organisations]. Aachen: Meyer and Meyer, 489-516.

Baur J and Burrmann U (2003) Konflikte in Sportvereinen [Conflicts in Sport Clubs]. In: Baur J and Braun $S$ (eds) Integrationsleistungen von Sportvereinen als Freiwilligenorganisationen [Integration Services of Sports Clubs as Voluntary Organisations]. Aachen: Meyer and Meyer, 331-370.

Baur J, Burrmann U and Nagel M (2003) Solidargemeinschaftliche Kleinvereine? Zum Einfluss vereinsstruktureller Merkmale auf Mitgliederbindung, vereinspolitische Partizipation und freiwilliges Engagement [Solidarity-based Small Clubs? On the Influence of structural Characteristics of the Club on Member Loyalty, Participation in Club Politics and voluntary Engagement]. In: Baur J and Braun S (eds) Integrationsleistungen von Sportvereinen als Freiwilligenorganisationen [Integration Services of Sports Clubs as Voluntary Organisations]. Aachen: Meyer and Meyer, 303-330.

Baur J and Mutz M (2009) Subjektive Integrationskonzepte der Ansprechpartner und Übungsleiter. [Subjective integration concepts of the contact persons and exercise leaders]. In: Baur J (ed) Evaluation des Programmes "Integration durch Sport" [Evaluation of the "Integration through Sport" Programme]. Potsdam: University of Potsdam, pp.155-181.

Becker S and Häring A (2012) Soziale Integration durch Sport? [Social integration through sport?]. Sportwissenschaft 42(4): 261-270.

Berry JW (2005) Acculturation: Living successfully in two cultures. International Journal of Intercultural Relations 29(6): 697-712.

Burrmann U, Brandmann K, Mutz M, et al. (2017) Ethnic identities, sense of belonging and the significance of sport: stories from immigrant youths in Germany. European Journal for Sport and Society 14(3): 186-204.

Burrmann U, Braun S and Mutz M (2020) In whom do we trust? The level and radius of social trust among sport club members. International Review for the Sociology of Sport 55(4): 416-436.

Coleman JS (1974) Power and the structure of society. New York, London: Norton. 
Dowling F (2020) A critical discourse analysis of a local enactment of sport for integration policy: Helping young refugees or self-help for voluntary sports clubs? International Review for the Sociology of Sport 55(8): 1152-1166.

Elling A and Claringbould I (2005) Mechanisms of inclusion and exclusion in the Dutch sports landscape: Who can and wants to belong? Sociology of Sport Journal 22(4): 498-515.

Elmose- $\varnothing$ sterlund K, Ibsen B and Breuer C (2016) Introduction to the project "Social Inclusion and Volunteering in Sports Clubs in Europe". Odense: University of Southern Denmark.

Elmose- $\varnothing$ sterlund K, Seippel $\varnothing$, Llopis-Goig R, et al. (2019) Social integration in sports clubs: individual and organisational factors in a European context. European Journal for Sport and Society 16(3): 268-290.

Esser H (2009) Pluralization or assimilation? Effects of multiple inclusion on the integration of immigrants. Zeitschrift für Soziologie 38(5): 358-378.

European Commission (2007) White Paper on Sport. Brussels: Commission of the European Communities.

Feld SL (1981) The focused organization of social ties. American Journal of Sociology 86(5): 1015-1035.

Gerber M and Pühse U (2017) Sport, Migration und soziale Integration: Eine empirische Studie zur Bedeutung des Sports bei Jugendlichen [Sport, Migration and Social Integration: An Empirical Study on the Importance of Sport among Young People]. Zürich: Seismo.

Heckmann F (2015) Integration von Migranten: Einwanderung und neue Nationenbildung [Integration of Migrants: Immigration and New Nation-Building]. Wiesbaden: Springer VS.

Hox JJ (2010) Multilevel Analysis: Techniques and Applications. New York: Routledge.

Hox JJ and MacNeish D (2020) Small samples in multilevel modeling. In: van de Schoot R and Miočević M (eds) Small Sample Size Solutions: London: Routledge, pp. 215-225.

Hoye R, Nicholson M and Brown K (2015) Involvement in sport and social connectedness. International Review for the Sociology of Sport 50(1): 3-21.

Janssens J and Verweel P (2014) The significance of sports clubs within multicultural society. On the accumulation of social capital by migrants in culturally "mixed" and "separate" sports clubs. European Journal for Sport and Society 11(1): 35-58.

Kahlert D (2009) Miteinander in Eintracht? Konflikte in integrativen Sportgruppen [Living together in harmony? Conflicts in integrative sports groups]. In: Baur J (ed) Evaluation des Programmes "Integration Durch Sport" [Evaluation of the "Integration Through Sport" Programme]. Potsdam: University of Potsdam, 367-383

Kalter F (2005) Reduziert Wettbewerb tatsächlich Diskriminierungen? Eine Analyse der Situation von Migranten im Ligensystem des deutschen Fußballs [Does competition indeed lessen discrimination? Analyzing the situation of immigrants in the German soccer league system]. Sport und Gesellschaft 2(1): 39-66.

Kleindienst-Cachay C, Cachay K, Bahlke S, et al. (2012) Inklusion und Integration: Eine empirische Studie zur Integration von Migrantinnen und Migranten im organisierten Sport [Inclusion and Integration: An Empirical Study on the Integration of Migrants in Organised Sport]. Schorndorf: Hofmann.

Kreft I (1996). Are multilevel techniques necessary? An overview, including simulation studies. Unpublished manuscript, University of California, Los Angeles. 
Krouwel A, Boonstra N, Duyvendak JW, et al. (2006) A good sport? International Review for the Sociology of Sport 41(2): 165-180.

Lamprecht M, Bürgi R, Gebert A, et al. (2017) Sportvereine in der Schweiz: Entwicklungen, Herausforderungen und Perspektiven [Sports Clubs in Switzerland: Developments, Challenges and Perspectives]. Magglingen: Bundesamt für Sport BASPO.

Lamprecht M, Fischer A and Stamm H (2014) Sport Schweiz 2014 [Sport Switzerland 2014]. Magglingen: Bundesamt für Sport BASPO.

Leszczensk L and Gräbs Santiago A (2015) The development and test of a measure of youth's ethnic and national identity. Methods, Data, Analyses 9(1): 87-110.

Lundkvist E, Wagnsson S, Davis L, et al. (2020) Integration of immigrant youth in Sweden: does sport participation really have an impact? International Journal of Adolescence and Youth 25(1): 891906.

Maas CJM and Hox JJ (2005) Sufficient sample sizes for multilevel modeling. Methodology 1(3): 86-92.

MacNeish DM and Stapleton LM (2016) The effect of small sample size on two-level model estimates: A review and illustration. Educational Psychology Review 28(2): 295-314.

Makarova E and Herzog W (2014) Sport as a means of immigrant youth integration: An empirical study of sports, intercultural relations, and immigrant youth integration in Switzerland. Sportwissenschaft 44(1): 1-9.

Marsh HW, Lüdtke O, Nagengast B, et al. (2012) Classroom climate and contextual effects: Conceptual and methodological issues in the evaluation of group-level effects. Educational Psychologist 47(2): 106-124.

Mutz M (2011) Sport als Sprungbrett in die Gesellschaft? Sportengagements von Jugendlichen mit Migrationshintergrund und ihre Wirkung [Sport as a Stepping Stone into Society? Sport Engagement of Young People with a Migration Background and its Impact]. Weinheim: Beltz Juventa.

Nagel S (2006) Sportvereine im Wandel: Akteurtheoretische Analysen zur Entwicklung von Sportvereinen [Sport Clubs in Change: Actor-Theoretical Analyses of the Development of Sport Clubs]. Schorndorf: Hofmann.

Nagel S, Elmose- Østerlund K, Adler Zwahlen J, et al. (2020a) Social integration of people with a migration background in European sports clubs. Sociology of Sport Journal 37(4): 355-365.

Nagel S, Elmose- Østerlund K, Ibsen B, et al. (eds) (2020b) Functions of Sports Clubs in European Societies: A Cross-National Comparative Study. Cham: Springer.

Nakagawa S and Schielzeth H. (2013) A general and simple method for obtaining $\mathrm{R}^{2}$ from generalized linear mixed-effects models. Methods in Ecology and Evolution 4(2): 133-142.

$\varnothing$ sterlund K and Seippel $\varnothing$ (2013) Does membership in civil society organizations foster social integration? The case of Danish voluntary sport organizations. Journal of Civil Society 9(4): 391413.

Seiberth K (2012) Fremdheit im Sport: Eine kritische Auseinandersetzung mit den Möglichkeiten und Grenzen der Integration im Sport [Foreignness in Sport: A Critical Examination of the Possibilities and Limits of Integration in Sport]. Schorndorf: Hofmann.

Seiberth K, Schlesinger T and Weigelt-Schlesinger Y (2013) Wie integrationsfähig sind Sportvereine? Eine Analyse organisationaler Integrationsbarrieren am Beispiel von Mädchen und Frauen mit 
Migrationshintergrund [What is the integrative capacity of sports clubs? An analysis of organizational barriers to integration based on the example of women and girls with an immigration background]. Sport und Gesellschaft 10(2): 174-198.

Seiberth K and Thiel A (2010) Cultural Diversity, Otherness and Sport: Prospects and Limits of Integration. In: Traue HC, Johler R and Gavrilovic JJ (eds) Migration, integration and health: The Danube region. Lengerich, Westf: Pabst Science Publishers, pp.189-203.

Snijders TAB and Bosker RJ (2012) Multilevel Analysis: An Introduction to Basic and Advanced Multilevel Modeling. Thousand Oaks, CA: Sage.

Spaaij R (2013) Cultural diversity in community sport: An ethnographic inquiry of Somali Australians' experiences. Sport Management Review 16(1): 29-40.

Stauder J (2014) Friendship networks and the social structure of opportunities for contact and interaction. Social science research 48: 234-250.

van Dick R, Wagner U, Adams C, et al. (1997) Einstellungen zur Akkulturation: Erste Evaluation eines Fragebogens an sechs deutschen Stichproben [Adjustment of an acculturation scale: An evaluation of a questionnaire on six German samples]. Gruppendynamik 28(1): 83-92.

Walseth K (2008) Bridging and bonding social capital in sport: Experiences of young women with an immigrant background. Sport, Education and Society 13(1): 1-17.

Weber M (1980 [1921]) Wirtschaft und Gesellschaft [Economy and Society]. Tübingen: Mohr. 
Table 1: Operationalization and descriptive statistics of the variables

\begin{tabular}{|c|c|c|}
\hline Variables & Operationalization & $\begin{array}{l}\text { Frequency } / \\
\text { mean (sd) }\end{array}$ \\
\hline \multicolumn{3}{|l|}{ Interaction } \\
\hline Item 1 & Other members respect me the way I am. & $4.60(0.91)$ \\
\hline Item 2 & No one in the club would notice my absence. (inv) & $3.91(1.09)$ \\
\hline Item 3 & I find it difficult to make social contacts in our club. (inv) & $4.42(1.01)$ \\
\hline Item 4 & $\begin{array}{l}\text { In our club, conflicts often arise between me and members from } \\
\text { other backgrounds. (inv) }\end{array}$ & $4.57(0.91)$ \\
\hline Interaction & Scale & $4.37(0.67)$ \\
\hline \multicolumn{3}{|l|}{ Leve1 1: Sociodemographics } \\
\hline Age & Number of years divided by 10 & $2.06(0.39)$ \\
\hline Gender & Dummy, 1 = female & $38.0 \%$ \\
\hline Education & $0=$ No school certificate $-5=$ Academic education & $3.01(1.29)$ \\
\hline \multicolumn{3}{|l|}{ Migration background } \\
\hline $\mathrm{PMB}_{16}$ & People with migration background in 1 . generation & $12.6 \%$ \\
\hline $\mathrm{PMB}_{2 \mathrm{G}}$ & People with migration background in 2 . generation & $20.0 \%$ \\
\hline Natives & Natives & $67.4 \%$ \\
\hline \multicolumn{3}{|l|}{ Leve1 1: Membership-biographics } \\
\hline Membership duration & Number of years in the club divided by 10 & $0.68(0.53)$ \\
\hline volunteering & Dummy, 1 = voluntary engagement & $49.4 \%$ \\
\hline Frequency of activity & $1=$ irregular $/$ rare $-4=$ several times per week and $\geq 3 \mathrm{~h}$ & $3.50(0.84)$ \\
\hline Participation in competition & Dummy, 1 = participation in competition & $73.7 \%$ \\
\hline Parents' sport club participation & Dummy, $1=$ (former) club participation of parents & $58.3 \%$ \\
\hline \multicolumn{3}{|l|}{ Leve1 1: Integration attitudes } \\
\hline No special treatmentindiv & No special treatment for $\mathrm{PMB}$; Agreement $1-5$ & $3.85(1.06)$ \\
\hline Respecting habitsindiv & Respecting habits of PMB; Agreement $1-5$ & $4.11(0.99)$ \\
\hline $\begin{array}{l}\text { Athletes from country of } \\
\text { origin }{ }_{\text {indiv (inv) }}\end{array}$ & $\begin{array}{l}\text { Some athletes should come from country of origin (inv); } \\
\text { Agreement } 1-5\end{array}$ & $2.74(1.36)$ \\
\hline \multicolumn{3}{|l|}{ Leve7 2: Situational variables } \\
\hline \multirow[t]{3}{*}{ Municipality size } & $1=$ inhabitants $<5,000$ & $9.4 \%$ \\
\hline & $2=$ inhabitants $5,000-49,999$ & $64.4 \%$ \\
\hline & $3=$ inhabitants $>=50,000$ & $26.3 \%$ \\
\hline \multirow[t]{3}{*}{ Club size } & $1=$ members $<200$ & $29.9 \%$ \\
\hline & $2=$ members $200-399$ & $20.0 \%$ \\
\hline & $3=$ members $>=400$ & $51.1 \%$ \\
\hline \multirow[t]{6}{*}{ Proportion PMB in the club } & $1=0 \% \mathrm{PMB}$ & $0.6 \%$ \\
\hline & $2=1-10 \%$ PMB & $32.3 \%$ \\
\hline & $3=11-25 \% \mathrm{PMB}$ & $18.6 \%$ \\
\hline & $4=26-50 \%$ PMB & $37.8 \%$ \\
\hline & $5=51-75 \%$ PMB & $7.2 \%$ \\
\hline & $6=>=76 \%$ PMB & $3.5 \%$ \\
\hline \multicolumn{3}{|l|}{ Leve7 2: club goa7s } \\
\hline Sociability & "Promoting sociability in the club"; Importance 1-5 & $3.97(0.89)$ \\
\hline Competition & "Engagement in top-class and competitive sport"; Importance 1-5 & $3.39(1.13)$ \\
\hline Integration & "Promoting the integration of PMB in the club"; Importance 1-5 & $3.44(0.82)$ \\
\hline \multicolumn{3}{|c|}{ Leve7 2: club-cultural, collective understanding of integration } \\
\hline No special treatmentagg & Club mean "No special treatment $t_{\text {indiv" }}$ & $3.85(0.28)$ \\
\hline Respecting habitsagg & Club mean "Respecting habitsindiv" & $4.11(0.31)$ \\
\hline $\begin{array}{l}\text { Athletes from country of } \\
\text { originagg (inv) }\end{array}$ & Club mean "Athletes from country of originindiv (inv)" & $2.74(0.47)$ \\
\hline
\end{tabular}


Table 2: Multilevel models for individual variables

\begin{tabular}{|c|c|c|c|}
\hline & Mode1 1 & Mode1 2 & Mode1 3 \\
\hline Age & & 0.03 & \\
\hline Sex (female) & & 0.06 & \\
\hline Education & & 0.02 & \\
\hline \multicolumn{4}{|l|}{ Migration background } \\
\hline $\mathrm{PMB}_{1 \mathrm{G}}$ & & $-0.29 * * *$ & $-0.33 * * *$ \\
\hline $\mathrm{PMB}_{2 G}$ & & -0.10 & -0.09 \\
\hline \multicolumn{4}{|l|}{ Natives (ref.) } \\
\hline Membership duration & & $0.10(*)$ & $0.11 *$ \\
\hline Volunteering (yes) & & $0.10(*)$ & $0.11 *$ \\
\hline Frequency of activity & & 0.05 & \\
\hline Competition sport (yes) & & 0.07 & \\
\hline Parents' vSC participation (yes) & & $0.08(*)$ & $0.09 *$ \\
\hline No special treatment $t_{\text {indiv }}$ & & $0.05 *$ & $0.05 *$ \\
\hline Respecting habitsindiv & & 0.02 & \\
\hline $\begin{array}{l}\text { Athletes from country of originindiv } \\
\text { (inv.) }\end{array}$ & & $0.09 * * *$ & $0.10 * * *$ \\
\hline Pseudo- $R^{2}$ (individual) & 0.00 & 0.14 & 0.12 \\
\hline Pseudo-R ${ }^{2}$ (club) & 0.00 & 0.25 & 0.36 \\
\hline Pseudo- $R^{2}$ GLMM(m) & 0.00 & 0.11 & 0.10 \\
\hline Pseudo-R ${ }^{2}$ GLMM(C) & 0.11 & 0.19 & 0.18 \\
\hline observations & 780 & 712 & 741 \\
\hline Groups & 42 & 42 & 42 \\
\hline
\end{tabular}


Table 3: Multilevel models for structural and individual variables

\begin{tabular}{|c|c|c|c|c|c|c|c|}
\hline & \multicolumn{2}{|c|}{ Situational } & \multicolumn{2}{|c|}{ Club goals } & \multicolumn{2}{|c|}{ club culture } & \multirow{2}{*}{$\begin{array}{l}\text { Fu11 mode } \\
\text { Mode } 17\end{array}$} \\
\hline & Mode1 1 & Mode1 2 & Mode1 3 & Mode1 4 & Mode1 5 & Mode1 6 & \\
\hline \multicolumn{8}{|l|}{ Migration background } \\
\hline PMB1G & $-0.32 * * *$ & $-0.47 * * *$ & $-0.33 * * *$ & $-0.45 * * *$ & $-0.33 * * *$ & $-0.48 * * *$ & $-0.57 * * *$ \\
\hline PMB2G & -0.07 & -0.05 & -0.09 & -0.08 & -0.09 & -0.05 & -0.04 \\
\hline \multicolumn{8}{|l|}{ Natives (ref.) } \\
\hline Membership duration & $0.11 *$ & $0.11 *$ & $0.10 *$ & $0.10 *$ & $0.11 *$ & $0.09(*)$ & $0.09(*)$ \\
\hline volunteering (yes) & $0.10 *$ & $0.09(*)$ & $0.10 *$ & $0.12 *$ & $0.10 *$ & $0.11 *$ & $0.10 *$ \\
\hline $\begin{array}{l}\text { Parents' vSC participation } \\
\text { (yes) }\end{array}$ & $0.09(*)$ & $0.09(*)$ & $0.09 *$ & $0.09 *$ & $0.09 \%$ & $0.09(*)$ & $0.09(*)$ \\
\hline No special treatmentindiv & $0.05 *$ & $0.05 *$ & $0.05 *$ & $0.05 *$ & $0.06 *$ & $0.06 *$ & $0.06 * *$ \\
\hline $\begin{array}{l}\text { Athletes from country of } \\
\text { originindiv (inv.) }\end{array}$ & $0.10 * * *$ & $0.10 * * *$ & $0.10 * * *$ & $0.10 * * *$ & $0.10 * * *$ & $0.10 * * *$ & $0.10 * * *$ \\
\hline \multicolumn{8}{|l|}{ Municipality size } \\
\hline Inhabit. $<5,000$ & $0.29 *$ & $0.28 *$ & & & & & 0.25 \\
\hline $\begin{array}{l}\text { Inhabit. 5'000-49'999 } \\
\text { Inhabit. } \geq 50 \text { '000 (ref.) }\end{array}$ & 0.12 & $0.14(*)$ & & & & & 0.16 \\
\hline \multicolumn{8}{|l|}{ Club size } \\
\hline Members $<200$ & $0.22 \%$ & $0.20 *$ & & & & & $0.16(*)$ \\
\hline Members 200-399 & 0.14 & 0.12 & & & & & 0.10 \\
\hline \multicolumn{8}{|l|}{ Members $\geq 400$ (ref.) } \\
\hline Proportion PMB & -0.02 & -0.05 & & & & & -0.05 \\
\hline * PMB1G & & $0.24 \% * *$ & & & & & $0.14(*)$ \\
\hline * PMB2G & & -0.01 & & & & & \\
\hline Sociability goal & & & 0.05 & 0.04 & & & \\
\hline Competition goal & & & -0.00 & -0.03 & & & -0.00 \\
\hline * $\mathrm{PMB}_{1 \mathrm{G}}$ & & & & $0.20 * *$ & & & $0.13(*)$ \\
\hline$* \mathrm{PMB}_{2 \mathrm{G}}$ & & & & 0.04 & & & \\
\hline Integration goal & & & 0.03 & -0.03 & & & -0.01 \\
\hline * $\mathrm{PMB}_{1 \mathrm{G}}$ & & & & $0.24 * *$ & & & 0.04 \\
\hline$* \mathrm{PMB}_{2 \mathrm{G}}$ & & & & 0.03 & & & \\
\hline No special treatment $t_{a g g}$ & & & & & -0.10 & -0.01 & -0.04 \\
\hline$* \mathrm{PMB}_{16}$ & & & & & & $-0.76 * *$ & $-0.54 *$ \\
\hline$* \mathrm{PMB}_{2 \mathrm{G}}$ & & & & & & 0.17 & \\
\hline Respecting habitsagg & & & & & 0.02 & -0.01 & \\
\hline$* \mathrm{PMB}_{16}$ & & & & & & -0.02 & \\
\hline$* \mathrm{PMB}_{2 \mathrm{G}}$ & & & & & & -0.08 & \\
\hline $\begin{array}{l}\text { Athletes from country of } \\
\text { originagg (inv.) }\end{array}$ & & & & & -0.02 & -0.07 & -0.05 \\
\hline * PMB $1 \mathrm{G}$ & & & & & & $0.65 * * *$ & $0.57 * * *$ \\
\hline$* \mathrm{PMB}_{2 \mathrm{G}}$ & & & & & & -0.05 & \\
\hline Pseudo- $R^{2}$ (individual) & 0.12 & 0.14 & 0.12 & 0.14 & 0.12 & 0.15 & 0.16 \\
\hline Pseudo- $R^{2}$ (club) & 0.54 & 0.60 & 0.32 & 0.42 & 0.30 & 0.46 & 0.63 \\
\hline Pseudo- $R^{2}$ GLMM(m) & 0.15 & 0.17 & 0.11 & 0.13 & 0.10 & 0.14 & 0.20 \\
\hline Pseudo-R ${ }^{2}$ GLMM(c) & 0.20 & 0.21 & 0.19 & 0.20 & 0.18 & 0.20 & 0.24 \\
\hline observations & 741 & 741 & 741 & 741 & 741 & 741 & 741 \\
\hline Groups & 42 & 42 & 42 & 42 & 42 & 42 & 42 \\
\hline
\end{tabular}

